\title{
Fetocolpos- A Rare Case of Transverse Vaginal Septum with Trapped Aborted Fetus
}

\section{Archana D Rathod ${ }^{1 *}$, Sandhya Pajai ${ }^{2}$ and Gaddikeri $\mathrm{A}^{3}$}

${ }^{1}$ Associate professor, obstetrics and Gynecology department, Govt Cancer Institute, Govt Medical College \& Hospital, India

2Professor \& Head of the Department of obstetrics \& Gynaecology, Shri. VN Govt medical College \& Hospital, India

${ }^{3}$ Senior Resident, Department of obstetrics \& Gynaecology, Shri .VN Govt Medical College\& Hospital, India

*Corresponding author: Archana D Rathod, Associate professor, obstetrics and Gynecology department, Govt Cancer Institute, Govt. Medical College \& Hospital, Aurangabad, Maharashtra, India, Tel: 9823273422; Email: archanarathod7@gmail.com

\section{Abstract}

Transverse vaginal septum is the result of faulty canalization of the embryonic vagina. We describe a very rare of perforate transverse vaginal septum was diagnosed during second pregnancy in abortion phase.

A $24 \mathrm{yr}$ old women with lactational amenorrhoea of 8 months presented to our obstetric emergency department with severe pain in lower abdomen. In obstetric history, she had undergone emergency caesarean section for vaginal atresia 8 months back. Pelvic and vaginal ultrasonograpghy, with gynecologic examination established a diagnosis of transverse vaginal septum.

An incision in the vaginal septum allowed us to see dead fetus, which was trapped in upper part of vagina. The diagnosis of transverse vaginal septum was confirmed during abortion phase \& excision of the septum will prevent future obstetric complications. This rare case will helpful in keeping mind when confronted with such presentation.

High index of suspicion is necessary to diagnose this type of anamoly. Gynecologists should be aware of the possibility of transverse vaginal septum in women in labour who became pregnant from a small central aperture. Correct \& timely diagnosis of transverse vaginal septum prevents maternal morbidity in the form of uterine rupture \& multiple significant vaginal lacerations \& will have good obstetric career.

Keywords: Trapped Fetus; Transverse Vaginal Septum; Müllerian Ducts; Abortion

\section{Introduction}

Any defect in the normal organogenesis involving the urogenital sinus or the müllerian duct can result in genital

tract anamolies [1]. Disorders of vertical fusion represent faults in the junction between down growing müllerion 
ducts and upward growing derivative of the urogenital sinus. A transverse vaginal septum was caused by incomplete fusion of the tissue that separates the vaginal plate and the caudal end of the müllerionducts. Transverse septa may be complete, resulting in cryptomenorrhoea and hematocolpometra or perforate with pinpoint openings allowing menstrual flow. We present the rare case of perforate transverse septum with fetocolpos, was diagnosed in abortive phase during second pregnancy.

\section{Case Report}

A 24-yrs old woman presented to our obstetric department complaining of pain in lower abdomen with lactational amenorrhoea of 8 months. Her obstetric history revealed that she had undergone emergency caesarean section 8 months back for vaginal atresia \& was advised for regular postnatal follow up. She did not turn up for follow up afterwards.

On per abdominal examination, uterine fundal height was of 18-20 weeks with contractions of high amplitude. Previous caesarean scar was seen with no scar tenderness. Per speculum examination revealed presence of only lower third part of vagina like blind pouch with small pinpoint opening in the centre of the pouch (Figure 1).

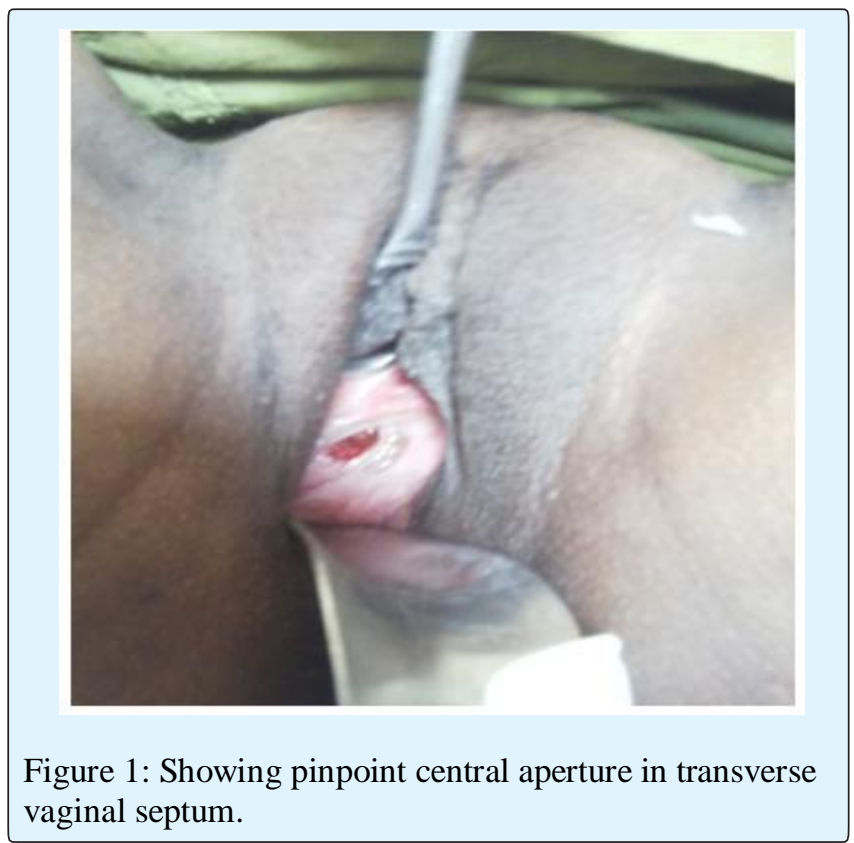

Pelvic and vaginal ultrasonography revealed single dead fetus of gestational age of 18 weeks seen trapped in the upper vaginal cavity behind a transverse vaginal septum was, suggestive of fetocolpos (Figure 2).

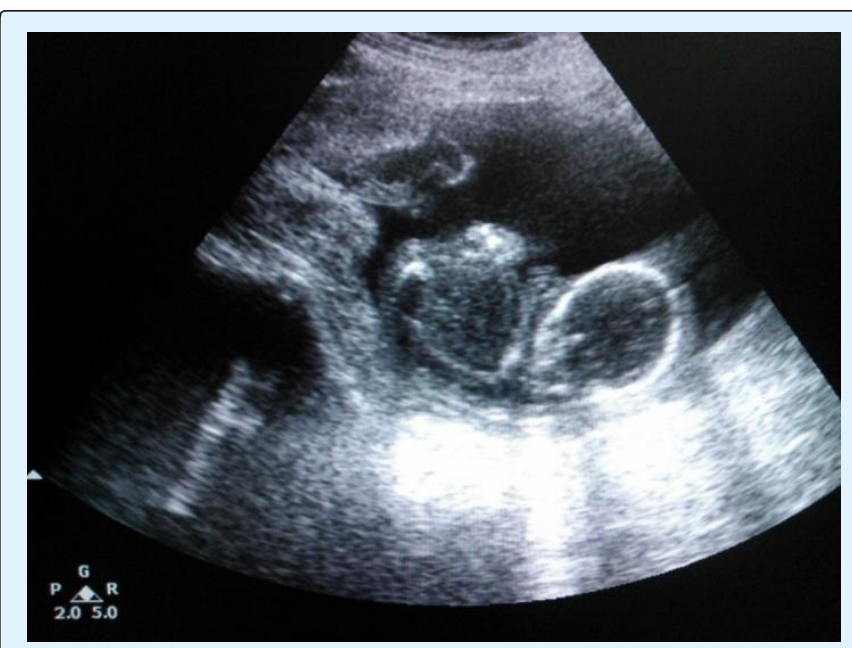

Figure 2: TVS picture of fetus in utero with tranverse vaginal septum.

Pelvic and vaginal ultrasonography with gynecological examination co-related with history established a diagnosis of incomplete transverse vaginal septum in mid vagina. As the fetus is trapped between upper vaginal portion and transverse vaginal septum, vaginal septum was resected and dead fetus was expelled out, under short general anesthesia. External os of the cervix was visualized, which was hidden behind transverse vaginal septum (Figure 3). The postpartum course of the patient was uneventful \& she had full recovery after 6 weeks follow up.

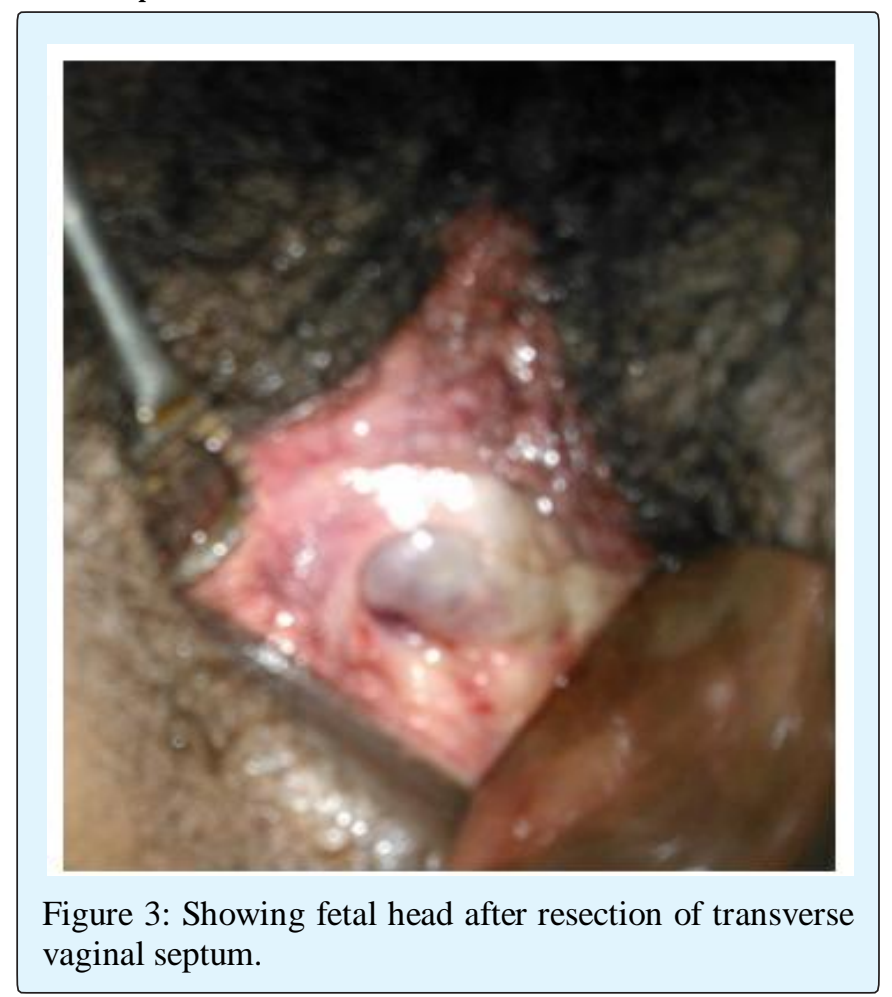




\section{Discussion}

In recent decades, advances in imaging modalities have facilited diagnosis of mullerian duct anomalies. The incidence of which is estimated as 0.001 to $10 \%$. First time in the literature, the rare case of an unusual presentation of müllerion anamoly, which is diagnosed during second pregnancy in abortive phase with fetocolpos is described in this case report.

In the complete transverse vaginal septum, the site of obstruction may occur at any point along the vaginal canal. But it is most frequently at the junction between the middle and upper thirds of the vagina.

Diagnosis of perforated transverse vaginal septum is difficult to detect due to absence of symptoms. Often an abdominal mass is noted \& exploration performed. The diagnosis is difficult because there is no bulging at the outlet. The onset of symptoms usually occurs after puberty, with the onset of menstruation.

An perforated transverse vaginal septum is usually asymptomatic and therefore does not require correction during childhood or early adolescence. The central aperture allows for vaginal secretion \& menstrual flow from the vagina. Transverse vaginal septum during pregnancy may be diagnosed as absence of vagina or short vagina. It may lead to significant vaginal lacerations or uterine rupture or to a caesarean delivery, if surgical correction not done prior to delivery. Surgical correction should follow an attempt to identity the extent of lesion.

Blanton described the management and outcomes of two gravidae with transverse vaginal septum first diagnosed during pregnancy $[2,3]$.

Esperanza Boutista Gomez, et al. also described such case with TVS diagnosed during pregnancy [4].

Such a transverse vaginal septum is occasionally mistaken for upper limit of the vaginal vault \& at the time of active labour, the opening in the septum is erroneously considered to be an undilated external os, like in our case. Transverse vaginal septum is a rare diagnosis to make during labour\& important to treat before uterus rupture.
To summarize, a high index of suspicion is necessary to diagnose this type of anamoly. Gynecologists should be aware of the possibility of transverse vaginal septum in women in labour who became pregnant from a small central aperture. Correct \& timely diagnosis of transverse vaginal septum prevents maternal morbidity in the form of uterine rupture \& multiple significant vaginal lacerations \& will have good obstetric career.

\section{Conflicts of Interest}

Archana Rathod, Sandhya Pajai, Gaddikeri declare that they have no conflicts of interest. Informed consent was obtained from patient included in the study. This article does not contain any studies with human or animal subjects.

\section{References}

1. Erum Khalid, SadiaJalil, Touquir Anwar, Sidrah Nausheen (2011) Congenital female genital tract abnormalities two years experience in a tertiary care hospital. Pak \& Surg 27(1): 44-49.

2. Caloia DV, Morris H, Rahmani MR (1998) Congenital transverse vaginal septum. Vaginal hydrosonographic diagnosis \& ultrasound Med 17(4): 261-264.

3. Blanton E N, Rouse D J (2003) Trial of labour in women with TV septa. Obstet Gynecol 101(52): 11101112.

4. Boutista GE, Morales GV, Flores-Romero AL, Pizarro ON, Velasquez VA (2012) Tabique vaginal transverse superior parcial y embarazo. Ginecolobstet Mex 80(7): 487-490. 